\title{
UNA EVALUACIÓN CRÍTICA DE LOS PROGRAMAS DE TRANSFERENCIA TECNOLÓGICA EN EL AGRO CHILENO
}

\author{
Boris Falaha LUMI. U. DE CHILE. L.S.C.I.- C.N.R.S. Francia
}

\section{INTRODUCCIÓN}

Este trabajo es el resultado de nuestros estudios realizados en terreno, durante los meses de enero, febrero y marzo de los años 1991 y 1992 y algunas visitas especificas.

Las áreas estudiadas se ubican en la VIII, IX y X regiones. También estuvimos en la Región Metropolitana y en IV Región, fuera del periodo estival.

Nuestro objetivo fue observar, estudiar y analizar las modalidades reales de funcionamiento y los efectos sociales de los Programas de Transferencia Tecnológica financiados por INDAP para capacitar a medianos y pequeños campesinos.

Entrevistamos fundamentalmente a los beneficiarios de los programas de formación de manera privada e individual. Posteriormente discutimos con los profesionales de capacitación de las áreas trabajadas, nuestras impresiones y los resultados de nuestras entrevistas. Tanto con los $\mathrm{CAT}^{*}$, los funcionarios de INDAP y capacitadores de las empresas de formación.

Esta confrontación de resultados con los profesionales del agro, originó seminarios y reuniones de trabajo, especialmente en ciudades como Temuco, Valdivia y Chiloé.

Utilizamos, asimismo, como fuente de información nuestra observación y participación en los cursos de cinco días que realizaban las ong especializadas en la formación de profesionales del sector agrícola.

En una primera evaluación de nuestro trabajo como capacitador e investigador en capacitación y desarrollo campesino efectuada en ICIRA (Instituto de Capacitación e Investigaciones de la Reforma Agraria) organismo mixto FAO - Gobierno de Chile, antes del golpe militar, constatamos que los campesinos formados en diferentes programas de capacitación (tales como cursos de cajero-bodeguero, contabilidad, uso de suelos, mejoramiento de praderas, poda, ganadería y Iechería, organización cooperativa, etc.), adquirían sin dificultad los conocimientos enseñados.

Sin embargo, más que el cumplimiento de condiciones pedagógicas o la adquisición de conocimientos, comenzamos por interrogarnos qué sucedía después con las personas formadas. La posformación se nos presentó como un tema de particular importancia en la evaluación de los programas de formación.

En un primer momento, observamos que los conocimientos adquiridos por los campesinos les servían para fundamentar y elaborar lógicas de trabajo y de participación asociativa muy diferentes de los objetivos generales de los cursos - que en una fase preliminar perseguían estimular una modalidad de trabajo cooperativo para optimizar el uso de recursos de trabajo y de gestión.

En dicha oportunidad constatamos el caso, ya citado por nosotros, que los campesinos formados para arar la tierra o para conducir y mantener una máquina agrícola, al finalizar sus cursos y a pesar de un perfecto aprendizaje teórico y práctico, de ser beneficiarios de tierras, capital y herramientas entregadas por la Reforma Agraria, preferían abandonar el campo y la agricultura y los encontramos en las ciudades (Santiago, Caracas o Dakkar) como choferes o cargadores de camiones.

*Consejos de Asistencia Técnica. 
El análisis de lo que pasa con las personas formadas (posformación) debe tomarse en cuenta al momento de planificar los cursos de capacitación. La pedagogía de adultos aunque sea muy acertada, pertinente y eficiente en la transmisión de conocimientos, no es nada más que un instante dentro del proceso social que desencadena.

La constatación de efectos previstos y no previstos en la posformación no puede ser imputada a un análisis incompleto o insuliciente de lo previsible, como afirman algunos especialistas, sino el resultado de la creación de nuevas lógicas de comportamiento, de nuevas creaciones sociales.

Este trabajo es, además, la continuación de otros anteriores efectuados en el sector campesino, en los cuales estudiamos los programas desarrollados por las oNG, y ha sido posible gracias a la participación del Laboratorio de Sociología de los Cambios Institucionales de París (L.S.C.I.) y a FLACSO.

En nuestras observaciones en terreno hemos considerado los siguientes paradigmas teóricos:

- que la formación de adultos o capacitación, además de transmitir conocimientos es una modalidad de intervención social;

- que produce efectos previstos y no previstos por los programas;

- que genera lógicas de comportamiento y relaciones sociales nuevas; y

- que las necesidades y los objetivos que los beneficiarios establecen en un comienzo de los programas son distintos a los que ellos mismos se fijan al término de un programa.

El objetivo general de este estudio apunta a comprender las dificultades que enfrenta el campesino para utilizar los conocimientos adquiridos, apropiarlos, establecer nuevas lógicas de trabajo, que le sirvan para aumentar sus recursos y, por ende, la producción y sus beneficios.

El subdesarrollo y la miseria de los campesinos ha durado largo tiempo. No creemos que este fenómeno sea natural ni tampoco que estén condenados a permanecer en esta situación. No aceptamos las afirmaciones escuchadas con frecuencia, que son por naturaleza flojos e incapaces de concebir una modernidad de mercado. En otros términos, no aceptamos las argumentaciones de tipo racista, por considerarlas carentes de base científica, en el sentido que es propio del mestizaje de nuestros campesinos su inferioridad productiva. Resulta sorprendente que aún hoy en día en Chile se use con frecuencia este tipo de argumentación. El análisis por lo natural ha reemplazado al análisis por la cultura.

\section{II. ÁMBITO DE ESTUDIO}

Nuestra modalidad de trabajo consistió en entrevistar a directivos regionales, jefes de áreas, responsables de programas, consejeros de asistencia técnica, propietarios o directivos de las empresas privadas de formación y extensionistas de dichas empresas.

Contactamos empresas antiguas - anteriores al actual período democrático- y, también, a aquéllas que participaron recientemente en la licitación de bonos de capacitación. Incluimos, además, a los beneficiarios de los programas de formación. En total, entrevistamos a 66 beneficiarios, en forma individual, y observamos reuniones grupales de trabajo realizadas por diversas empresas.

Las localidades abarcadas fueron las siguientes:

- En la Octava Región: Chillán, Coihueco, San Carlos, Portezuelo, Ninhue, Coelemu, Cobquecura; Los Ángeles, Mulchén, Alto Biobío;

- en la Novena Región: Vilcún, Cunco y Melipeumo; Nueva Imperial, Carahue, Puerto Saavedra, Lobería y Tovolhue; 
UNA EVALUACIÓN CRÍTICA DE LOS PROGRAMAS...

- en la Décima Región: las columnas de Paillaco, Valdivia, Osorno, Puerto Montt, Calbuco, Maullín, Carelmapu;

- en la Isla Grande de Chiloé visitamos programas en Ancud, Castro, Chonchi y Quellón; y

- en la Región Metropolitana, Colina, Chacabuco y Caleu.

Tratamos de visitar programas efectuados por diferentes empresas. El valioso concurso prestado por INDAP nos permitió elegir los lugares más representativos de situaciones reales y frecuentes en las diversas zonas, incluso lugares muy alejados de los centros urbanos que, en algunas épocas del año, no pueden ser visitados.

Tenemos la impresión que lo logramos, por cuanto al término de las visitas constatamos que la modalidad de trabajo, así como también los problemas y la motivación de los campesinos se repetían. Además, después del análisis de las entrevistas, aunque éstas sean limitadas, logramos establecer perfiles sociales de los beneficiarios de los programas que podríamos clasificar en el grupo de los exitosos.

\section{CARACTERÍSTICAS DE LOS PROGRAMAS Y SUS BENEFICIARIOS}

En 1982, en el mismo momento que INDAP pasaba por una crisis que puso en juego su propia existencia, algunos de los profesionales de la institución formularon un nuevo programa de capacitación que superara al anterior, que se hallaba muy desacreditado (Programa ATE), en funcionamiento desde 1978.

\subsection{Programa de Transferencia Tecnológica Integral}

El nuevo programa propuesto obtuvo apoyo técnico de oDEPLAN, apoyo político del gobierno y respaldo financiero del Banco Mundial. Se concibió como un conjunto de acciones educativas individuales y grupales (predominando las primeras) dirigidas a los campesinos medianos y pequeños, con el propósito de cambiar conductas productivas y, de este modo, lograr un aumento de sus ingresos.

Desde el punto de vista teórico se estructura sobre la base de cuatro elementos que son: Capacitación, divulgación, asistencia técnica e investigación. Dichos elementos forman parte de un programa integral único, que se ejecuta en todas partes por un mismo consultor, mediante acciones de carácter grupal e individual.

Acciones de grupo*: orientadas a entregar asistencia técnica individual (visita al predio) y realizar investigación basándose en la toma de registros y la realización de estudios complementarios.

Acciones individuales*: destinadas a entregar los elementos de capacitació, a través de "reuniones técnicas" y los de divulgación, medinate "días de campo".

Los beneficiarios se reúnen en grupos con características agroecológicas semejantes (un mismo sector territorial), pero no siempre poseen los mismos niveles de formación y sus predios tienen montos de inversión diferentes. La semejanza agroecológica no es sinónimo de semejanza socio-profesional.

Cada grupo está formado por 22 personas. Tres grupos equivalen a un módulo, lo que hace un total de 66 campesinos (cantidad máxima que puede atender un extensionista). Éste, a su vez, cuenta con la asesoría de un jefe técnico, que debe ser ingeniero agrónomo, veterinario u otro profesional habilitado.

*Registro INDAP 1989-1991. 


\section{REVISTA DE SOCIOLOGÍA}

Teóricamente, además, los programas tienen que corresponder a proyectos de desarrollo agrícola.

Existe un plan anual de trabajo de los extensionistas (PATE) al cual dichos profesionales deben ceñirse. La ejecución de este Plan es requisito para que se efectúen los pagos correspondientes a las empresas que realizan la capacitación.

Los campesinos que optan al programa deben presentar una solicitud de admisión, que conlleva el otorgamiento del bono de financiamiento de INDAP a la empresa patrocinante y, cada vez que el extensionista los visita en terreno, los campesinos le firman un formulario de control.

Cada extensionista del programa está autorizado para atender, personalmente, a un máximo de 66 campesinos que constituyen un módulo, dividido en tres grupos de 22 campesinos cada uno, como ya lo dijimos. Tales cifras son las óptimas, aunque también se pueden conformar grupos con un mínimo de ocho y un máximo de 26 integrantes. El director de INDAP es el único que tiene la facultad de autorizar al funcionario de la empresa de capacitación para que atienda a un número mayor o menor de beneficiarios por grupo.

Las visitas individuales del extensionista son nueve al año por cada campesino. Las del médico veterinario, dos anuales (financiadas en un $100 \%$ por el programa).

Las actividades grupales consisten en dos reuniones técnicas anuales por grupo; un día de campo al año por grupo y dos visitas a parcelas demostrativas anuales por grupo.

Los agricultores que postulan a ser beneficiarios del Programa de Transferencia Tecnológica Integral, deben cumplir con los siguientes requisitos:

- ser productores silvo-agropecuarios;

- explotar una superficie máxima de 12 H.R.B.;

- que sus activos no superen las UF 3.500;

- que sus ingresos provengan mayoritariamente de la explotación agrícola;

- Trabajar directamente la tierra, cualquiera sea su régimen legal o tenencia.

Los arrendatarios y/o medieros, además de cumplir con los requisitos mencionados, deben tener contratos de acuerdo a la ley vigente.

En el aspecto financiero, el conjunto de acciones que se desarrollan en beneficio del campesino se expresan a través de un Bono de Transferencia Tecnológica, fijado en UF. En cuanto a las visitas del extensionista dicho bono cubre sólo el $80 \%$ de su valor. En cambio las visitas del médico veterinario y las actividades grupales, reciben un $100 \%$ de subvención. En este último caso, deben asistir al menos un $40 \%$ de los campesinos integrantes del grupo para que la empresa pueda cobrar su bono.

En lo que se refiere a la cuota parte, como veremos más adelante, son muy pocos campesinos los que la pagan, encargándose habitualmente la empresa de absorberla.

Aparte de INDAP, como institución del Estado, de la empresa de formación (que es una organización privada sometida a una reglamentación) y de los beneficiarios, existe un cuarto actor que es el Consejero de Asistencia Técnica (CAT). A él le corresponde verificar que las empresas cumplan con las obligaciones establecidas en el contrato, e INDAP le paga por el trabajo realizado.

En la práctica, los CAT, efectúan una función contralora, aunque no llegan a cubrir la totalidad de los beneficiarios de los módulos que se les asigna. Por ello verifican una muestra por área por empresa de transferencia. Su deseo es que, en el futuro, su tarea de controlar se convierta en una labor de asesoramiento.

Para ocupar el cargo de Consejero de Asistencia Técnica, el requisito fundamental es poseer el título de ingeniero agrónomo o médico veterinario. 


\subsection{Programa de Transferencia Tecnológica Básica}

El Programa, de Transferencia Tecnológica Básica comenzó a desarrollarse a partir de los años 1987 y 1988 y obedeció, en gran parte, a la necesidad de conducción política del gobierno militar. Al respecto, cabe recordar que era un régimen caracterizado por un orden impuesto y una ausencia de organizaciones campesinas.

En la actualidad el, PTTB también es necesario para el gobierno democrático, pues se ve en él una herramienta para expandir el número de beneficiarios de la transferencia tecnológica, orientándolos a aspectos comunitarios y familiares, a través de acciones grupales.

Este programa, como el anterior, representa un conjunto de acciones y servicios educativos y técnicos destinados a cambiar los comportamientos tecnológicos.

En su versión 90-91 amplía su campo de acción para integrar al campesino a la comunidad nacional, contribuyendo así a mejorar su situación actual.

Sus beneficiarios son minifundistas, campesinos de bajo ingresos, pertenecientes a un estrato socioeconómico inferior a los beneficiarios del PTT. Igual que el anterior, este programa está estructurado por cuatro elementos que son: capacitación, divulgación, asistencia técnica e investigación. Las acciones señaladas se realizan a través de actividades individuales y grupales.

La actual formulación de bases comprende tres áreas fundamentales: desarrollo predial (cultivos tradicionales: papas, lentejas, frutales caseros, ganado menor); desarrollo de la familia (cuyas líneas principales de trabajo son: nutrición, higiene ambiental, mejoramiento del equipo del hogar e incorporación de huertos familiares); desarrollo comunitario, que busca integrar a las personas a las actividades comunales, acceso de los jóvenes al trabajo y acceso a las actividades sociales y productivas (juntas de vecinos, asociaciones de productores, cooperativas). Los dos últimos aspectos (desarrollo de la familia y desarrollo comunitario) revisten particular relevancia para el programa.

Los requisitos para optar al Programa de Transferencia Tecnológica Básica, son los siguientes:

- ser pequeños productores minifundistas (eso les da la posibilidad de obtener una parte de sus ingresos fucra del predio);

- Cumplir con los requisitos para ser beneficiario de INDAP, entre los cuales se halla no tener deudas pendientes;

- residir en la comuna donde se va a desarrollar el programa.

Los módulos básicos del programa están constituidos por cuatro grupos que pueden tener un mínimo de 13 y un máximo de 24 beneficiarios.

A diferencia del PTTI, este programa cubre acciones dedicadas enteramente a la mujer. Tales acciones están a cargo de una pareja de extensionistas (hombre y mujer) y por un segundo extensionista hombre.

Privilegia las acciones de tipo grupal por sobre las intervenciones individuales, diferenciándose en tareas dirigidas a los hombres y a las mujeres.

El PTTा en cambio no contempla aspectos de desarrollo familiar y actividades comunitarias.

Las intervenciones pedagógicas se distribuyen de la siguiente manera:

- Visitas individuales: cuatro para hombres y cinco para mujeres al año;

- Actividades grupales: tres reuniones técnicas para hombres y tres para mujeres; y un día de campo para hombres y uno para mujeres.

En los programas de Transferencia Tecnológica 1991-1992, se producen modificaciones que disminuyen las visitas individuales y aumentan las actividades grupales. 


\section{REVISTA DE SOCIOLOGIA}

Existe también la posibilidad de efectuar un día de campo familiar y/o reuniones productivas (una por grupo para hombres y una por grupo para mujeres).

El PTrB tiene especificidades y modalidades distintas que se expresan en tres proyectos para beneficiarios minifundistas, con ciertas características propias:

- los comuneros de la IV región;

- los minifundistas de secano; y

- el sector minifundista mapuche.

Lo anterior, lo diferencia también del PTT, que es uno solo para todo el país.

En el aspecto financiero, su financiamiento proviene íntegramente del Estado. Por lo tanto, los campesinos no aportan ninguna suma de dinero. En consecuencia, las empresas no deben agregar a su costo el no aporte campesino. El valor de la subvención por beneficiario en la temporada era de 13,68 UF*, para las comunidades de la IV Región y de 16,11 UF* para los proyectos del sector secano y los minifundistas mapuches.

Las visitas efectuadas por los extensionistas tienen que quedar registradas en un libro de visitas y recomendaciones.

Las actividades de investigación del programa consisten en el establecimiento de un registro predial por cada grupo de agricultores atendido por el extensionista productivo (hombre) y uno por cada grupo de familias atendidas por la extensionista familiar.

Finalmente, cabe señalar que los campesinos pueden aceptar o rechazar incorporarse a algún programa, pero no pueden elegir la empresa que les dará formación. No hay impedimento expreso, sin embargo, en la práctica se da así.

\subsection{Cobertura de Ambos Programas}

El número de agricultores atendidos por los programas de Transferencia Tecnológica Integral y Básico se muestra en el siguiente cuadro:

Cuadro 1

Número de agricultores atendidos por los programas de Transferencia Tecnológica Integral y Básico

\begin{tabular}{|cccc|}
\hline Año & Integral & Básico & Total \\
\hline $1983-1984$ & 13.140 & - & 13.140 \\
$1984-1985$ & 13.865 & - & 13.865 \\
$1985-1986$ & 13.608 & - & 13.608 \\
$1986-1987$ & 13.951 & - & 13.951 \\
$1987-1988$ & 19.280 & 6.855 & 26.115 \\
$1988-1989$ & 18.553 & 7.029 & 29.582 \\
$1989-1990$ & 15.887 & 11.066 & 26.953 \\
$1990-1991$ & 15.048 & 11.070 & 26.118 \\
$1991-1992$ & 14.916 & $26.985^{2}$ & 32.958 \\
\hline
\end{tabular}

1 P.T.T.B. adjudicados en septiembre 1990.

${ }^{2}$ Fuente: INDAP.

*Valores correspondientes al año agrícola 90-91. 


\section{4. ÁREAS CONFLICTIVAS DE FUNCIONAMIENTO}

Como consecuencia del análisis de los comportamientos de los campesinos frente a los programas de formación, nosotros podemos señalar algunas áreas-conflicto o temas-problemas que encontramos en todos los lugares visitados. Tales como problemas relacionales, permanencia prolongada y repetición de los cursos, irregularidades en las visitas a terreno de los técnicos, ausencia de control o evaluación de la adquisición de conocimientos, carencia de material pedagógico (situación mejorada en 1992), dicotomía total entre política crediticia y política de capacitación y políticas de desarrollo, ausencia de capacitación empresarial y comercial.

\subsection{Problemas relacionales INDAP-Beneficiario-Empresa}

Conviene recordar que las empresas de transferencia tecnológica deben presentar una lista de los solicitantes que desean optar al subsidio otorgado por INDAP para los programas de capacitación. Luego, INDAP verifica la lista y su control se limita a asegurarse que los postulantes cumplan con los requisitos exigidos. La nómina de candidatos permite a la empresa seleccionada recibir los bonos de capacitación correspondientes al número de inscritos en su programa.

Tal como se observa en los hechos a la empresa le interesa agrupar a los campesinos para que no excedan de una zona geográfica determinada. A tal propósito, establece contacto con los vecinos de aquéllos que han aceptado inscribirse y persuade a los que se muestran reticentes. Una gran dispersión de los beneficiarios significaría a la empresa mayores costos de transporte y de tiempo para efectuar las visitas.

Los campesinos interrogados sobre este particular señalaron, en forma unánime, que ingresaron al programa porque se los solicitaron. Les aseguraron que ésa era la condición o ello les facilitaría el acceso al crédito.

En la práctica, es el propio funcionario de la empresa cl que se encarga de gestionar el crédito a los campesinos. Además, las empresas les conceden créditos directos para la adquisición de productos sanitarios y agrícolas. Lo anterior, se debe a que no sólo actúan como agencias de asistencia técnica, sino también como servicios de venta agroveterinarios*.

Otro de los argumentos que, comúnmente, esgrimen para que los campesinos se decidan a inscribirse es que ello les dará derecho a dos visitas gratis anuales del veterinario y a una tercera gratis, o a la mitad de precio, en caso de urgencia.

Uno de los campesinos entrevistados por nosotros nos dijo, por ejemplo, que él ingresó motivado por el hecho de que su sobrino se desempeñaba como extensionista.

Las empresas, para asegurarse un número determinado de campesinos y el máximo de bonos ofrecen a los interesados algunas ventajas tales como la gestión de créditos ante INDAP - sirviendo ellos como intermediarios-, así como también el otorgamiento de créditos directos para adquirir preferentemente abonos, pesticidas, semillas y productos veterinarios; la posibilidad de beneficiarse en su predio con una parcela demostrativa financiada por la empresa. Les aseguran, asimismo, la gratuidad de los cursos y, así, la cuota parte que legalmente deben pagar los campesinos (20\%) corre por cuenta de la empresa. En el caso de los productores de leche, puede llegar a descontarse mensualmente a través de la entrega de leche a las centrales lecheras. Estas últimas y las empresas de formación, se prestan mutuo apoyo en tal aspecto. Sin embargo, en Valdivia, una empresa lechera anunció la suspensión de tal tipo de descuento porque no podía continuar encargándose de su gestión y administración.

*INDAP ha modificado esa reglamentación a partir de junio de 1991. 


\section{REVISTA DE SOCIOLOGIA}

Los campesinos interrogados al respecto (aquellos que no eran productores de leche) contestaron unánimemente que ellos no pagaban por el programa de formación y que pagaban sólo las visitas extraordinarias del vèterinario y los medicamentos, que solían costarles muy caros. Los productores de leche, en cambio, afïmaban que la cuota parte se les descontaba. Otros no estaban seguros si se les efectuaba el descuento.

Los responsables de las empresas y los extensionistas nos informaron que ellos recuperaban entre un 20 a un $25 \%$ de la participación financiera de los campesinos y que, al inicio del programa, el valor de los bonos permitía prescindir sin problemas del aporte de ellos.

En la actualidad, se preguntan cómo cambiar esta situación. Por ejemplo, algunas empresas fijan tarifas menores que la cuota oficial, para recuperar algún porcentaje. Es frecuente también que los campesinos, al momento de la cosecha, les recompensen con productos o la engorda de algún animal.

Cabe destacar que en un seminario de capacitación*, dirigido a profesionales del agro, se reconoció que un $80 \%$ de los campesinos no pagaba por los programas y que las empresas, en ese sentido, los habían malacostumbrado.

En la zona de Chonchi, por ejemplo, a comienzos del año pasado, un grupo de doce personas, de un total de veinte, abandonó el programa al exigírseles el pago de su cuota-parte correspondiente al año 1990.

De otros entrevistados recibimos respuestas evasivas, como "Esa es una cuestión de INDAP"; o bien, que ellos pagan por el hecho de firmar los formularios de visita, señalando que con ello le hacen el sueldo a los extensionistas y se quejan porque, a pesar de ello, éstos pasan a la carrera, no observan con cuidado los cultivos y no examinan detenidamente a sus animales. "El veterinario de ahora no es como el de antes que examinaba a los animales con una linterna y equipo", sostienen.

Por su parte, los extensionistas nos indicaron lo difícil que les resulta llegar a establecer una relación de confianza con los campesinos quienes, a veces se niegan a firmarles los formularios de visita.

Uno de los beneficiarios, de Paillaco, viudo, de 45 años de edad, con dos hijas mayores, cuyo padre fue beneficiario de la Caja de Colonización y de quien heredo 66 hectáreas arables y 80 hectáreas de monte, nos manifestó que si los extensionistas no llegaban antes de las 7:00 A.M. él se negaba a firmarles la boleta de visita, afirmando que a esa hora podían examinar a sus animales cuando se hallaban en el establo, antes de echarlos a los potreros.

Cuando le señalamos que era imposible visitar a todos los campesinos a la misma hora, declaró que él pagaba, que era uno de los pocos que lo hacía y, por lo tanto, tenía derecho a exigir que lo visitaran a la hora fijada por él.

Nos dijo, también, que las visitas del agrónomo o del técnico agrícola no tenían tanta importancia para él como las del veterinario, pues poseía diez vacas lecheras, novillos de crianza, terneras y lanares.

Se sentía muy orgulloso de su campo. Es propietario de una camioneta nueva, que conduce su hija, y le sirve para transportar sus animales a la feria y movilizarse. Para que sirviera a sus propósitos le adaptó una carrocería de madera. Sin embargo, se niega a asegurar su vehículo. Según él, su hija maneja muy bien y nadie se atreverá a estropeárselo, porque en la zona lo conocen y aprecian. Además, nos expresó su satisfacción por la posibilidad que se le brindaba de obtener créditos, la mejoría de sus empastadas y el aumento de su producción lechera.

* Seminario organizado en Valdivia por el GIA y el PIIE. 
En suma, éste es el caso de una persona que podriamos clasificar como un beneficiario "feliz", aunque nos dijo que se veía obligado a sostener una dura lucha para no acatar siempre las recomendaciones que le formulaba el extensionista en lo referente a abonos e insecticidas que, a su juicio, resultaban excesivas.

Nosotros tuvimos la oportunidad de visitar detenidamente su predio. Nos mostró un cajón de unos $90 \mathrm{~cm}$ de ancho por unos $2,50 \mathrm{~m}$ de largo en el cual mezclaba sus semillas y fertilizantes. Consideraba que ésa era la manera más adecuada para homogeneizar y mejorar los rendimientos y él la había aprendido de un terrateniente de la zona de Rupanco.

Sorprendidos le preguntamos "¿Cómo no lo aprendió en el programa de transferencia tecnológica?", y nos contestó: "No, ellos sólo dejan anotado en una hoja lo que uno tiene que hacer, pero no le explican cómo hacerlo. Si uno se fija se puede dar cuenta que los otros vecinos que participan en el programa no saben mezclar. Esto que digo lo comprobé en una parcela experimental. Yo, en cambio, doy vuelta mis nueve sacos hasta que la mezcla toma un color homogéneo y en seguida los ensaco nuevamente".

Al solicitarle que nos mostrara los formularios de visita, sólo pudo encontrar dos, aunque su hija aseguraba guardarlos todos. Las indicaciones contenidas allí son muy negligentes y no tienen valor pedagógico. Las observaciones anotadas por el veterinario, salvo en un caso, resultan ilegibles.

Cuando comentamos esta situación en el área respectiva, nos manifestaron que no tenía importancia, porque la mayoría de los campesinos no sabía leer.

Al respecto, la insuficiencia es casi total. En ningún caso encontramos un cuaderno de seguimiento o un archivo. En una sola ocasión hallamos una carpeta proporcionada por la empresa de transferencia. Si las boletas existen, están en completo desorden, son prácticamente ilegibles y carecen de valor pedagógico. Si se pueden leer, se limitan a dar instrucciones:"

Nuestro entrevistado no se mostraba particularmente preocupado por este asunto, y sólo se limitó a comentar: "Los campesinos sabemos cómo hacer las cosas". Cuando le recordamos que él era un urbano que había regresado al campo a causa de la muerte de su padre, nos replicó que había nacido en el campo y vivido allí hasta los doce años de edad. Luego había regresado a los 32 , después de haber desempeñado al menos diez oficios urbanos distintos. Agregó que acostumbraba ir a mirar a todas partes. Así había aprendido a mezclar sus semillas y fertilizantes. También nos informó que había seguido un curso de enfermero organizado en central de capaciación por el IER. Nos mostró, a modo de ejemplo, la carrocería de su camioneta, de modelo diferente al que se fabrica habitualmente en Osorno, diseñada por él. Reconocía, eso sí, haber cometido un error al calcular la altura de los galpones, que le quedaron demasiado bajos para sus necesidades.

Durante nuestra extensa conversación nos mostró con gran entusiasmo su predio y nos confidenció que estuvo a punto de perderlo. Se lo iban a rematar y logró vender sus animales a tiempo (que en su opinión no estaban adaptados a la región) y pudo compensar el alza del valor de las UF. No obstante lo anterior, estaba satisfecho porque se había deshecho rápidamente de aquellos animales que, a su modo de ver, no servían para nada.

Le preguntamos dónde los había obtenido, manifestó que de la empresa que lo atendía. $\mathrm{Al}$ interrogarlo si habían sido revisados por el veterinario, nos contestó que aparentemente sí, pero insistió en que no estaban adaptados a la zona.

El ejemplo descrito es el de un campesino excepcional, con una historia rural interrumpida, una experiencia urbana prolongada y una capacidad de adaptación, como ya hemos apreciado.

*INDAP ha dado instrucciones para superar esta dificulta, junio 1991. 


\section{REVISTA DE SOCIOLOGIA}

Dicho caso y otras entrevistas realizadas, nos permite afirmar que existe una enorme confusión en los derechos, responsabilidades y funciones que le corresponden al campesino, a INDAP y a las empresas de formación y falta de control de calidad de insumos.

\subsection{Permanencia prolongada de los beneficiarios y repetición de los cursos}

El programa de transferencia tecnológica se inició el año 1983 y estaba previsto que durara tres años. Se estimaba que un acompañamiento de tres períodos agrícolas consecutivos bastaría para obtener resultados. Pero se fue prolongando y ha venido favoreciendo a los mismos beneficiarios.

Nosotros conocimos a un gran número de personas que llevaban ocho o nueve años de permanencia en el programa. Preguntamos sobre el particular a los jefes de área y responsables de diferentes comunas y obtuvimos el resultado de la mínima rotación de los beneficiarios y la permanencia de la gran mayoría de ellos desde el inicio del prograna, aun cuando hubiera cambios en las empresas de formación.

La situación descrita plantea una enorme difïcultad para evaluar la verdadera adquisición de conocimientos. INDAP evalúa desde el punto de vista financiero y de utilización de los recursos humanos en los programas. No hace una evaluación de los conocimientos ni de la apropiación tecnológica. Por lo tanto no se puede saber en qué grado de avance se halla cada uno de los campesinos. Ello dificulta la progresividad del avance y la posibilidad que los campesinos se inserten en niveles superiores de aprendizaje o se postulen a cursos de capacitación especializada. Esta ausencia de logica del aprendizaje va acompañada por la presencia de la lógica del acompañamiento o del apoyo. Predomina la lógica de lo relacional sobre el aprendizaje.

Una prolongada continuidad en los cursos nos parece absurda, pues frena la adquisición de nuevos conocimientos e impide el acceso de nuevos beneficiarios, sin que los que permanecen en forma indefinida obtengan reales beneficios.

Una readecuación de los programas debe considerar este aspecto, así como también, el hecho que un Programa de Transferencia Tecnológica no es un fin en sí, sino un camino o un nivel dentro de un proceso mucho más largo y complejo de apropiación de nuevas tecnologías.

Otro punto que debe tomarse en cuenta, es que los campesinos no adquieren una verdadera autonomía. Si a ellos se les formula tal observación, responden que "sicmpre se aprende algo nuevo" o "Que es la única manera de obtener créditos" o que les significa dos visitas anuales gratuitas del veterinario y una tercera a mitad de precio (el precio de una consulta fluctúa alrededor de $\operatorname{los} \$ 10.000)$.

En 1987 se intentó terminar con los programas que llevaban seis años de escolaridad. La idea era dividirlos en dos grupos: agricultores en programa que recibirían la totalidad de lo establecido y agricultores en capacitación o divulgación (dirigido a aquellos beneficiarios que habiendo alcanzado cierto nivel técnico, necesitaban mantener aún cierto flujo de información tecnológica por medio de la asistencia a las actividades grupales).

La experiencia de interrumpir los cursos no dio resultado y, muy luego, se volvió a la situación anterior, renovándose los contratos por tres años más. Los campesinos que no iban a seguir con la formación se sintieron excluidos de la asistencia técnica y de la política crediticia y solicitaron su reincorporación.

Lo expuesto demuestra la alta tasa de permanencia de los campesinos en los programas. Apenas se da una rotación de $20 \%$ en ocho años. Las últimas causas para el retiro de los campesinos son enfermedad, venta del predio, cambio de actividad, deceso, cxigencia de pago de la cuota-parte.

Por otro lado, a pesar de las críticas que formulan al programa, la mayoría de ellos sigue sí 
para no perder las ocho visitas de carácter agronómico y dos del veterinario, así como por el acceso al crédito que éste les facilita. Hay que recordar que, además, el curso casi en su totalidad es gratuito para los inscritos.

Aquéllos que logran un mayor avance dentro del grupo, consideran que los más atrasados constituyen un lastre, sobre todo en lo que se refiere a la posibilidad de experimentar con nuevas variedades y sistemas de riego y fertilización y entienden que los técnicos no pueden avanzar más rápido en las explicaciones porque hay algunos que no las comprenden. Pero, concluyen, finalmente la gente aprende algo porque, prácticamente, todos los años se repiten las mismas charlas.

En la zona de Chiloé, por ejemplo, se dedican a cultivar la papa, las empastadas, algunos huertos familiares e higiene de los lanares. En el caso de los vacunos y la lechería se repiten los mismos rubros con la introducción de algunas variedades forrajeras (coles, nabos, maíz, etc.).

Una de las críticas que expresan los beneficiarios, se refiere a que se les enseña muy pocas variedades de cultivo y una vez que se han dedicado a la lechería les resulta muy difícil abandonarla.

Cerca de Castro uno de los campesinos nos manifestó que apenas pagara su crédito de animales, dejaría la crianza de vacas lecheras para dedicarse exclusivamente a los lanares y nos demostró que la crianza de ovinos era muchísimo más rentable.

Le preguntamos por qué se había dedicado a la lechería y nos indicó que así se lo recomendaron y que únicamente le concedían créditos productivos para el desarrollo de actividades lecheras. Pero, nos dijo, después de estas experiencias estaba decidido a cambiar de rubro.

En la zona mencionada existe, efectivamente, una presión para desarrollar la lechería y aunque la venta de leche representa un ingreso cotidiano, no existe certeza que sea la mejor opción económica para los campesinos. Por lo menos así lo indican otros proyectos de desarrollo impulsados por algunas ONG en esa misma área. Vale decir, la implantación de la tecnología lechera, se halla muy ligada al establecimiento de la industria lechera.

En forma paralela a la lógica de la empresa de formación que busca la inversión de insumos, hay también en las zonas lecheras una lógica por incentivar la producción impulsada por las industrias dedicadas al rubro.

Desde otro punto de vista, los volúmenes relativamente bajos de producción de los pequeños productores y la escasez de centros de acopio, determinan que éstos obtengan bajos precios de venta.

Durante un día de campo en Los Ángeles, oportunidad en que se reunió un módulo completo, con material pedagógico escaso, se produjo un interesante debate sobre la experiencia de un centro de acopio de leche en Temuco, que los integrantes de dicho módulo habían visitado.

Allí se recordó que la experiencia de Temuco se realizó con el aporte financiero de las industrias lecheras de esta ciudad y no estaban seguros que las industrias lecheras de su zona pudieran tener la misma actitud.

Casos como éste, nos permiten ver que las personas sometidas a largos programas de formación (vale decir, que se constituyen en pequeños grupos centrados en la adquisición o apropiación de conocimientos) son capaces de percibir la necesidad de realizar proyectos de desarrollo (comercialización o transformación) y orientarse - a través de una dinámica grupalhacia la constitución de grupos centrados en tareas comerciales, financieras o productivas. Reiteramos que la capacitación o transferencia tecnológica no puede analizarse solamente como adquisición de conocimiento o apropiación de tecnologías, que en la actualidad tienen un amplia gama de denominaciones (apropiadas, altemativas, orgánicas, ecológicas, etc.), sino que debe constituirse en grupos centrados en tareas, en contratos de desarrollo.

No se trata que los campesinos sepan cómo hacer un huerto orgánico, sino que queden en 
condiciones de comprender los impactos y ejecutar las acciones tendientes a modificar los sistemas y subsistemas productivos de su economía familiar.

Nos volveremos a referir a este tema cuando abordemos la capacitación por rubros.

\subsection{Carencia de material pedagógico}

Los programas de transferencia tecnologica debieran incluir una ficha de instrucción, observación y comentarios, con la obligación que el técnico la deje en cada lugar visitado. De la misma manera, el médico veterinario, tendría que consignar sus instrucciones y/o recomendaciones.

El material actualmente en uso, aun cuando sea legible, consiste en hojas sueltas. Convendria usar un cuaderno de recomendaciones fácil de conservar y consultar. Las hojas aludidas, contienen indicaciones sobre lo que el campesino tiene que hacer, pero no incluyen elementos "instructivos".

En los días de campo y en las parcelas demostrativas, el extensionista dicta su charla, que suele ser muy clara y amena, ayudándose de un rotafolio. Sin cmbargo, el único material que reciben los campesinos es una breve hoja de resumen que no tiene los gráficos mostrados por el extensionista.

La subutilización del material gráfico, nos parece una insuficiencia producida por la mala calidad del servicio o la gestión, pues no se debe al costo adicional que implicaría la preparación del material, sino que no se distribuye entre los asistentes. Por otra parte, los trípticos o fichas pedagógicas relativas al tema, están totalmente ausentes.

A la falta de cuadernos y fichas pedagógicas, hay (jue agregar que los campesinos no tienen acceso a otros materiales pedagógicos disponibles (tales como revistas técnicas y profesionales).

Al respecto, podemos señalar que el material pedagógico de los cursos de autoinstrucción, elaborado por la FAo y dirigido a pequeños campesinos, a pesar que es conocido por los profesionales de INDAP (en Puerto Montt, por ejemplo) las empresas de formación no lo utilizan, ni llega a manos de los campesinos. Se evidencia una subutilización del material disponible y apropiado.

Un programa de capacitación desprovisto de material pedagógico de acompañaniento pierde gran parte de su eficacia.

\subsection{Ausencia de evaluación de la adquisición cle conocimientos (apropiación)}

El esquema del programa de transferencia tecnológica no incluye un sistema de evaluación de los conocimientos impartidos. Contempla, al menos en teoría, mediciones de los rendimientos productivos, por rubros, logrados por los beneficiarios de los programas.

Después de un cierto aumento de la producción por rubro se observan "estancamientos" o "techos" en el volumen de producción. Este fenómeno solamente puede comprenderse mediante la evaluación y análisis de un conjunto de variables que influyen en el proceso productivo.

La enseñanza de conocimientos, su adquisición y utilización, no son la misma cosa. Es necesario, entonces, establecer claras diferenciaciones para poder evaluar con cierto rigor los programas de capacitación y estudiar de manera diversilicada los efectos sociales y económicos de dichos programas.

No es posible pretender que un programa de transferencia tecnológica, por muy bien elaborado y ejecutado que sea, cubra todas las necesidades de capacitación requeridas por el campesino. Si a lo anterior, sumamos que tales necesidades son permanentes en el tiempo, un programa de ransferencia tecnológica dirigido a los campesinos estí obligado a complementarse, articularse, con todos los demás cursos de capacitación existentes en la actualidad (enfermero de 
ganado, realizado por el IER, u otros) y, también, a actuar dentro de un marco general de capacitación y desarrollo campesino.

La evaluación justa de conocimientos permite su reconocimiento en otros programas y el establecimiento de módulos progresivos. No se trata de un plan nacional de capacitación, sino de evaluar los programas otorgándoles una mayor movilidad y articulación entre cllos.

En los seminarios dirigidos a profesionales de INDAP y las empresas de formación, en el transcurso de los cuales se estudiaron, en forma crítica, los programas de transferencia tecnológica, se insistió particularmente en las modalidades de trabajo individual o grupal y no se hizo hincapié en el problema de la evaluación de conocimientos y su apropiación. Tampoco en los debates de plenarios se concedió mayor importancia al problema de los niveles de aprendizaje.

\section{Capacitación por rubro y desarrollo predial}

Aun siendo la capacitación por rubros un buen instrumento que debiera permitir constatar con mayor facilidad los logros de los campesinos de bajos ingresos, no consigue introducir en el proceso productivo los recursos que el campesino posee. Habría que conseguir la posibilidad que, a partir del plan de desarrollo por predio, se utilicen acciones o estrategias horizontales de producción (interrubros). Nos parece muy importante la aplicación interrubros, porque una apropiación tecnológica cobra sentido y se transforma en realidad cuando se inserta en un conjunto de problemas y soluciones para la producción cotidiana.

No hablamos de soluciones tecnológicas aisladas, sino de conjuntos o situaciones tecnológicas. Tales situaciones (que los campesinos experimentan en sus predios) tendrían que servir de punto de partida para la capacitación tecnológica. No se trata de hacer diagnósticos descriptivos de recursos existentes o diagnósticos proyectivos (programas de recursos, planes de explotación), sino diagnósticos críticos de su funcionamiento de sus economías prediales y extraprediales, en las cuales se hallan hoy insertos.

La capacitación por rubros no incila a la confección de planes de explotación o de desarrollo por beneficiario (por predio). De igual manera, los llamados diagnósticos, propuestos por algunas ONG, no son otra cosa que la suma descriptiva de recursos existentes y no determinan los problemas reales de funcionamiento y conflicto que se presentan en un predio o en una comunidad.

Se requiere, por lo tanto, establecer un diagnóstico en desarrollo. El diagnóstico para que tenga sentido en el desarrollo no puede ser descriptivo y estático, sino dinámico y crítico. La noción de cambio - clave de todo desarrollo, independiente de sus orientaciones políticas o técnicas- no puede permanecer ausente de los programas de desarrollo.

No podemos silenciar el hecho que la existencia de una ideología naturalista y esencialista (predominante en el campo) resulta difícilmente compatible con un análisis del "estar en las situaciones" y del "cambio", implícitos en las políticas de desarrollo.

\subsection{Dicotomía entre política crediticia, política de desarrollo y política de capacitación}

El título de esta sección, aparentemente, estaría en contradicción con lo expresado anteriormente, en el sentido que las empresas de formación cmplean el crédito como acicate, como motivación, para lograr que los campesinos se incorporen a los programas.

La utilización del crédito como argumento de persuasión, no determina la existencia de una articulación entre el costo de los créditos, los resultados comparativos de producción y los beneficios obtenidos. Cabe recordar que existen cultivos ricos en inversión de insumos.

La citada articulación, se hallaba ausente en las parcelas demostrativas o experimentales que 
nosotros visitamos. El crédito se concibe como un insumo indispensable (semilla certificada, abonos, etc.), pero no es relativizado en modalidades específicas de utilización.

Por ejemplo, la cantidad de nutrientes en las empastadas — con su modalidad específica de utilización- era cuestionada por los campesinos. Uno de ellos manifestó que, siguiendo los consejos dados por otra empresa de capacitación que el uso de un pequeño cerco eléctrico le resultaba mucho más económico.

En otra oportunidad, un agricultor nos indicó que él no pudo sacar las malezas a causa de las lluvias, pero estaba casi seguro que le iba a resultar más barato que gastar en deservantes. La utilización de manera diferenciada de los insumos y los resultados económicos (no solamente los productivos) los observamos en el caso de la cooperativa campesina asesorada por OPDECH, en Chiloé, y en las parcelas "demostrativas" a tamaño real (14 há) que posee el CET, en la misma región.

No tuvimos la certeza que las afirmaciones de los campesinos fueran verdaderas. Sin embargo, eso no es lo realmente imponante, sino en la comprobación de que en los días de campo y en las parcelas demostrativas, no se efectuaba un análisis de costo comparativo, así también que el programa de capacitación no incluye los aspectos financicros y de gestión predial.

Tal ausencia de contenidos en materias financieras podría tener su explicación en que los programas de transferencia tecnológica (tanto el básico como el integral) se basan en la capacitación por rubros. Sin embargo, una adecuada capacitación por rubro no implica una ausencia de análisis financiero comparativo y gestión predial.

La situación se toma aún más crítica y reveladora porque los programas de transferencia tecnológica, no van ligados a un programa de desarrollo predial para cada campesino.

Los planes de desarrollo local sólo se mencionan para cumplir con los reglamentos administrativos de asignación de bonos. En consecuencia, el campesino desconoce, en su predio, la existencia de una estrategia o política de cambio en la utilización de sus suelos, de sus recursos actuales y de los recursos adicionales que puede obtener por medio del crédito.

En todas las comunas visitadas constatamos un problema específico surgido a raíz del otorgamiento de créditos para la adquisición de animales.

Dicho problema presenta dos aspectos críticos.

\subsubsection{Dificultades de pago provocadas por el desconocimiento del sistema financiero}

Sobre el particular, algunos campesinos nos señalaron que si hubieran sabido la forma de operar del sistema y la constante alza del precio de la ur, jamás se hubieran endeudado. Habrían preferido comprar uno o dos animales al contado en lugar de endeudarse para adquirir cinco o seis. Por otra parte, hay que considerar que el desarrollo de los planteles exige un mínimo de seis vacas. Lo anterior, involucra una fuerte dependencia financiera - que en un mercado libre y fluctuanteles produjo pérdidas irreparables, quiebra, venta de sus terrenos y, en el mejor de los casos, han necesitado seis a ocho años para recuperarse.

\subsubsection{Adaptación, estado sanitario y alimentación de los animales}

Al respecto, los campesinos se quejaron que los animales entregados no son aptos para la zona, que vienen de fuera, que llegan débiles, que los reproductores no vienen en óptimas condiciones y que han debido tenerlos durante seis meses en engorda antes de ponerlos con las hembras. A nuestro juicio, los promotores de los créditos no solamente debieran asegurarse de las condiciones jurídicas y financieras de la operación, sino que en su calidad de profesionales de promoción y desarrollo tendrían, primero que verificar el estado sanitario de los animales al momento de la 
entrega en el predio y, luego, que el campesino disponga de las empastadas o cultivos necesarios para alimentarlos.

Los programas de transferencia tecnológica y los planes de desarrollo suponen la introducción de un elemento capacitador nuevo (conocimiento). No sólo habría que asegurar las garantías financieras sino, también, la existencia de posibilidades de saber utilizar los bienes obtenidos mediante el crédito.

Creemos que resulta fácil verificar si el campesino realizó los trabajos previos a la recepción de los animales, a fin de cerciorarse que existen las condiciones necesarias para aprovechar la inversión efectuada.

Casi todos los directivos reconocieron este tipo de "falencias" y, sobre ellas, nos dieron las siguientes explicaciones:

a) que INDAP poseía una débil capacidad de negociación comercial y que, como hay pocos centros de abastecimiento, recibe los rezagos de las partidas de animales disponibles;

b) que los veterinarios u otros técnicos de la recepción de animales no cumplen eficazmente su labor de control y que es posible que hasta existan ciertas comisiones de venta pagadas por los proveedores. A ello se suma la debilidad de los campesinos para constatar o reclamar controles por la calidad de los animales. Según lo manifestado por ellos mismos, si reclaman no les entregan los animales y tampoco podrían obtener otros en mejor estado, por cuanto son los únicos disponibles. En este caso, la expresión popular "peor es nada", cobra todo su sentido.

\subsection{Ausencia de capacitación empresarial y comercial}

Conjuntamente con las insuficiencias observadas respecto a la separación de las políticas crediticias y las de desarrollo, así como la orientación exageradamente rubrista de los programas, encontramos una ausencia total de capacitación para la gestión empresarial, financiera y comercial de los beneficiarios.

Podríamos concordar con el hecho que mejorar un rendimiento por rubro, significara un aprendizaje empresarial para el agricultor. La diferencia, sin embargo, estriba en que el análisis de la gestión empresarial no puede limitarse a un éxito por rubro.

También nos sorprendió que los conocimientos de contabilidad, de comercialización, estuvieran ausentes. El seguimiento experimental y de investigación que implica el programa resulta con anotaciones incompletas, que no permiten extraer un provecho conceptual.

Convendría preparar cursos de conocimientos específicos de contabilidad, gestión predial o comercialización, que sucedan al prTT. Ello permitiría superar la lógica del apoyo, del seguimiento y de lo relacional, introduciendo, nuevamente, una lógica del aprendizaje.

El tema del predominio de lo relacional en los cursos fue, también, observado por nosotros en los programas de capacitación de las oNG*.

\section{CONCLUSIONES}

Los programas de formación se manifiestan en varias dimensiones: conocimiento, crédito, mejoramiento de suelos, ganadería, semillas, atendiendo a los requerimientos de los campesinos, pero no logran integrar los requerimientos en un proyecto de acción o de desarrollo ni, tampoco, preparar a los campesinos como un actor que esté en condiciones de negociar proyectos de desarrollo a partir de la formación recibida.

*Véase Boris Falaha, "Estrategias de formación de adultos y políticas de desarrollo en democracia", DT. 450, FLACSO, mayo 1990. 
Nosotros nos preguntamos, si el objetivo de la formación es solamente transmitir conocimientos y no generar un proyecto específico de desarrollo.

En segundo término, tampoco la formación logra, a pesar de la duración de los cursos, preparar a los campesinos para negociar y establecer estrategias de desarrollo con las instituciones públicas, financieras y privadas.

A raíz de esta ausencia de resultados podría establecerse que el objetivo de la capacitación no se limite a la mera transmisión de conocinientos u obtención de créditos, sino al logro de un verdadero contrato de formación-desarrollo.

Nuestras observaciones en la región del Ñuble, respecto al impacto que producía, en muy poco tiempo, la introducción de nuevas tecnologías (como el tabaco) muestran que esos mismos campesinos atendidos por el PTT son capaces, con otras reglas del juego de aprender, asimilar nuevas tecnologías y cultivos y negociar proyectos económicos y comerciales (como en la firma de acuerdo para cultivar tres hectáreas de tabaco).

Tales ejemplo y otros ya señalados, indican las limitaciones de los programas de transferencia tecnológica, fïnanciados por INDAP.

Hoy, más que nunca, el programa de transferencia tecnológica debe concebirse como herramienta de apoyo para el establecimiento de proyectos de desarrollo logrados por los campesinos. Aún los más pobres conciben, con modestos recursos, proyectos de mejoramiento de su trabajo.

No podemos seguir concibiendo la formación como una manera de ayudar a los campesinos pobres dándoles cultura, crédito y técnica, sino tenemos que ayudarles a la ejecución de tareas y proyectos específicos. No basta con enseñarles cómo alimentar el ganado para que sean capaces de incorporar de manera viable y económica vaquillas preñadas a su predio. Para ello es necesario implementar un conjunto de medidas a bajo costo (inferior al costo de las reses) para que esta operación resulte exitosa.

En otros términos, constatamos un paralelismo entre las acciones pedagógicas (transmisión de nuevos conocimientos) y los programas de desarrollo.

Nosotros pensamos que más que reflexionar sobre los conocimientos técnicos y tecnológicos que requiere el campesino para elevar su nivel de ingresos, hay que incitarlo para que después de cuatro años de formación de programa de transferencia tecnológica, formulen proposiciones para su desarrollo productivo. INDAP debería evaluar estos miniproyectos y a partir de dicha evaluación, establecer un acuerdo contractual con los campesinos para la ejecución del miniproyecto propuesto que fije la responsabilidad de las partes.

La adquisición de conocimientos es beneficiosa para todos, pero lo que en verdad importa a los campesinos es que se les brinde asesoría para la elaboración de miniproyectos, considerando las dificultades que presenta la economía de libre mercado.

El desarrollo campesino no debe ser infrapredial ni de asistencia social, sino permitirle insertarse en una economía extrapredial. 